\title{
Single-Pass Cladding Process Using Hot-wire Gas Metal Arc Welding Technique
}

\author{
Pattanawit Suntiniwat ${ }^{1}$, Eakkachai Warinsiriruk ${ }^{1, *}$, and Sutep Joy-A-Ka ${ }^{2}$ \\ ${ }^{1}$ Department of Industrial Engineering, Faculty of Engineering, Mahidol University, Thailand \\ ${ }^{2}$ Material Properties and Failure Analysis Laboratory, Material Properties Analysis and Development Centre, Thailand Institute of \\ Scientific and Technological Research, Thailand
}

\begin{abstract}
The aim of this study is to improve cladding process productivity by high production rate with low dilution process by specifying technique as hot-wire GMAW process. The base metal of carbon steel A516 Gr70 was cladded by austenitic stainless steel 309LSi for creating a buttering layer and stainless steel 308LSi for hot-wire filler for topping a cladding layer in a one-pass run. The studied parameters this experiment consist of the feeding ratio of hot wire feeding speed per GMAW wire feeding speed and travel speed. Welding phenomenon during welding was observed by CCD camera with specifying the optical device to see the appropriate condition. The result showed the hot-wire GMAW cladding process could reduce cycle time 3.5 times compare with conventional FCAW cladding process. Moreover, dilution of this process could decrease lower than $15 \%$ with acceptable FN 3 on the top of weld surface. Therefore, single pass cladding process achieved by using this method with low dilution by still keep microstructure capability.
\end{abstract}

\section{Introduction}

Arc welding processes $[1,2]$ often use cladding process in pressure vessel industry for the economic purpose such as small area or repairing event. Flux-cored arc welding (from here use as FCAW) has been used for cladding process since as high productivity and having good arc stability. Generally, a clad thickness layer has been desired not over 3 millimeters in case of general acid service for austenitic stainless steel. However, in reality, buttering layer which was created by the FCAW has a dilution ratio more than $30 \%$. It is necessary for the multi-pass run to get an appropriate microstructure for a service condition. Therefore, a clad thickness become over 3 millimeters. Also, productivity is low because it has a long waste time for getting a specified interpass temperature, an interpass cleaning, and grinding.

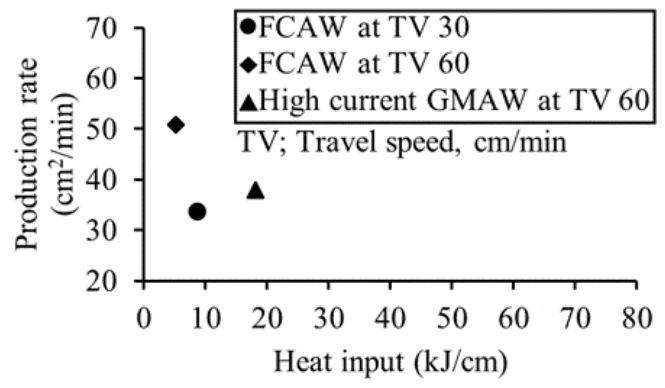

Fig. 1. The comparison of conventional cladding processes on production rate.

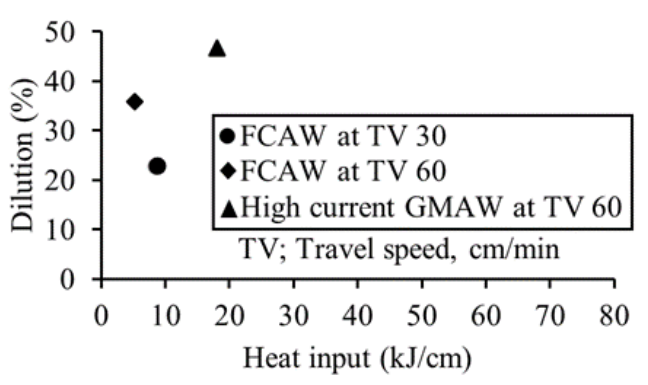

Fig. 2. The comparison of conventional cladding processes on dilution.

Modern welding process have been developed to improve deposition rate by using hot-wire gas tungsten arc welding (GTAW) process [3], [4]. The hot-wire GTAW process has potential to independent control of the wire current and wire feeding speed. The hot-wire method is heating filler wire up to the melting point by Joule heating and uses heat energy from the primary source to melt filler wire. Therefore, the addition of hotwire to conventional welding process has achieved low heat input with low dilution.

In this research have the purpose of developing cladding process for corrosion resistant by using Gas metal arc welding process and hot-wire method to build up cladding surface with a one-pass running for improving production rate in width area. Fig. 3 shows the schematic of hot-wire GMAW for a proposed process. 
Table 1. Chemical composition of base metal and filler wires.

\begin{tabular}{|c|c|c|c|c|c|c|c|c|c|}
\hline \multicolumn{10}{|c|}{ Base metal } \\
\hline Materials (\% mass) & \multicolumn{2}{|c|}{$\mathrm{C}$} & \multicolumn{2}{|c|}{$\mathrm{Mn}$} & \multicolumn{2}{|l|}{$\mathrm{P}$} & $\mathrm{S}$ & \multicolumn{2}{|c|}{$\mathrm{Si}$} \\
\hline Carbon steel A516 Gr 70 & \multicolumn{2}{|c|}{0.27} & \multicolumn{2}{|c|}{ (0.85-1.20 } & \multicolumn{2}{|l|}{0.035} & 0.035 & \multicolumn{2}{|c|}{$0.15-0.40$} \\
\hline \multicolumn{10}{|c|}{ Filler wires } \\
\hline Materials (\% mass) & $\mathrm{C}$ & $\mathrm{Cr}$ & $\mathrm{Ni}$ & Mo & $\mathrm{Mn}$ & $\mathrm{Si}$ & $\mathrm{P}$ & $\mathrm{S}$ & $\mathrm{Cu}$ \\
\hline SS ER309LSi & 0.02 & 23.60 & 13.40 & 0.11 & 1.8 & 0.79 & 0.02 & 0.001 & 0.1 \\
\hline SS ER308LSi & 0.02 & 19.79 & 10.24 & 0.014 & 2.25 & 0.78 & 0.03 & 0.03 & 0.75 \\
\hline
\end{tabular}

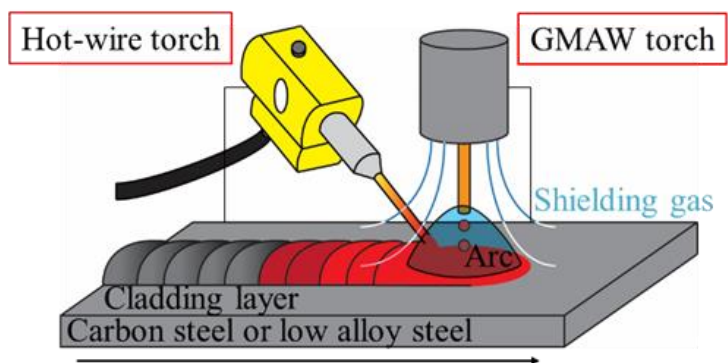

Welding direction

Fig. 3. Schematic of hot-wire GMAW process for build up cladding layer within one pass.

\section{Experiment procedure}

\subsection{Materials and specimen}

Carbon steel A516 Gr 70 was used for base metal and was prepared as an illustrates in Fig. 4. This developed process is mixing both of stainless steel filler wires, E309LSi with diameter $1.2 \mathrm{~mm}$ was used for GMAW to create bettering layer and ER308LSi with diameter 1.2 $\mathrm{mm}$ was used for hot-wire to create cladding layer in the conventional welding process. The chemical compositions of base metal and filler wires were showed in Table 1.

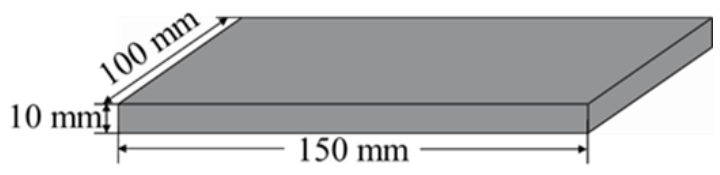

Fig. 4. Specimen dimension of base metal.

\subsection{Experimental setup and welding conditions}

Fig. 5 shows the schematic for setup of two welding torches and welding parameters shown in Table 2. The arc voltages were varied from 29,31 and 33 voltages for study the effect of voltage on bead size because increasing of arc voltage caused long arc length that affects spreading, wider weld bead. The increasing amount of filler wire could improve weld bead size. Therefore, the hot-wire feeding ratios were varied to studied effect of weld bead size as well. The hot-wire ratio was the ratio of hot-wire feeding speed $\left(\mathrm{HW}_{\mathrm{fs}}\right.$ : $\mathrm{m} / \mathrm{min}$ ) per GMAW feeding speed $\left(\mathrm{GMAW}_{\mathrm{fs}}: \mathrm{m} / \mathrm{min}\right)$ as shown in an equation (1).

$$
\text { Feeding ratio }=H W_{f s} / G M A W_{f s}
$$

Hot-wire feeding ratios were varied from $0.3,0.5$ and 0.7. Based on joule heating concept, the hot-wire currents were varied follow the increasing of hot-wire feeding ratio as 75, 125 and 175 ampere, respectively. According to a production rate in Fig. 1, high travel speed could improve production rate in width area. Therefore, the travel speed from 30, 40, 50 and 60 $\mathrm{cm} / \mathrm{min}$ were varied to study the effect of weld bead size as well. The arc current was fixed at 290 ampere with feeding speed at $13 \mathrm{~m} / \mathrm{min}$ and $20 \mathrm{~mm}$ wire extension length used for GMAW process which got the same production rate in width area same as conventional cladding process by FCAW. The wire feeding angle was fixed at $30^{\circ}$ with $70 \mathrm{~mm}$ of power supply distance for hot-wire condition. The mixing of Argon and $\mathrm{CO}_{2} 5 \%$ were used for shielding weld pool at flow rate $20 \mathrm{~L} / \mathrm{min}$.

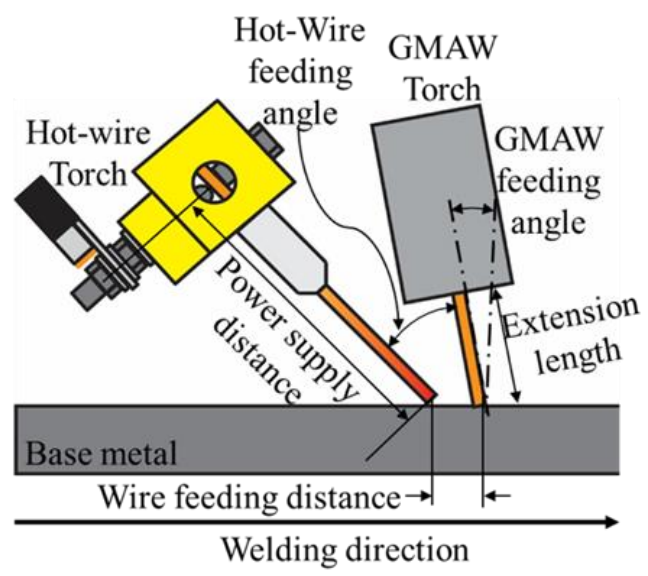

Fig. 5. Schematic of adjustment parameter of hot-wire GMAW process.

Table 2. Cladding parameters for hot-wire GMAW.

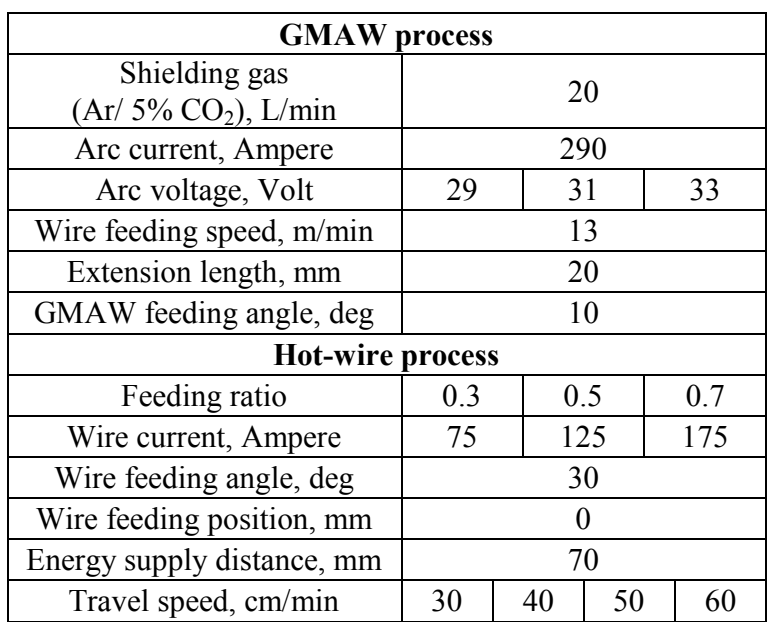




\subsection{Observation of process phenomena}

The welding phenomenon was observed by using CCD camera with $950 \mathrm{~nm}$ band-pass filter during actual welding.

\section{Results}

\subsection{Effect of cladding parameters on weld bead appearance}

Fig. 6 shows the welding phenomena of cladding bead formation under the effect of GMAW voltage and travel speed were observed by CCD camera. By all of the conditions in this Fig. performed by hot-wire feeding ratio as 0.7 with wire current 175 ampere. At 31 and 33 volt, cladding bead could be created good shape even though high feeding ratio was used. Poor bead appearance was a result of GMAW arc voltage of 29 volt, non-alignment occurred during start welding as shown in Fig. 6. Insufficient arc energy rarely obtains a good wetting of weld pool then caused non-alignment. It was understood that if arc voltage was too low with high feeding ratio, the unstable wire feed occurred during welding and caused a defect on weld bead. It was found that using the arc voltage of 31 volt with high travel speed as $60 \mathrm{~cm} / \mathrm{min}$ could obtain the acceptable weld bead. Consequently, single pass cladding achieved to weld by Hot-wire GMAW with appropriate arc voltage more than 31 volt.

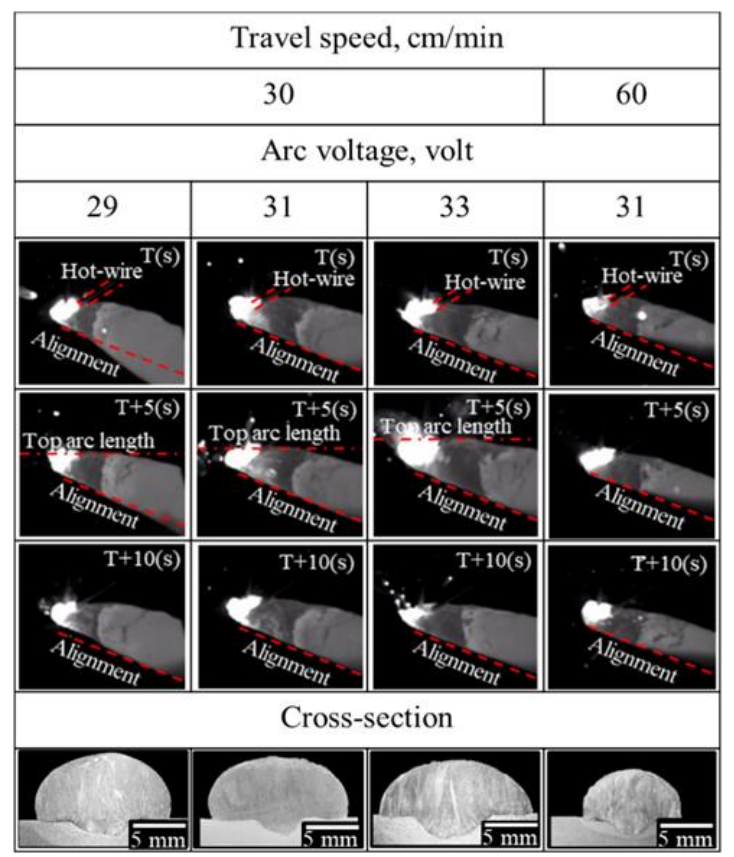

Fig. 6. Evidences of cladding bead formation from CCD camera and cross-section.

\subsection{Effect of cladding parameters on weld bead height}

Fig. 7 shows the weld bead height results at arc voltage 29,31 and 33 volt and comparison of normal GMAW with variations of hot-wire feeding ratio from $0.3,0.5$ and 0.7 by wire currents were varied follow feeding ratio as 75,125 and 175 ampere respectively with travel speed at $30 \mathrm{~cm} / \mathrm{min}$. Comparison of common GMAW, increasing of hot-wire feeding ratio of $0.3,0.5$ and 0.7 increases the height of cladding bead by $19 \%, 25 \%$, and $33 \%$, respectively. Moreover, the addition of hot-wire achieved cladding layer within one pass with same arc voltage of a common GMAW which welded only buttering layer. The result of arc voltage variation as shows cross-section in Fig. 6, the increasing of voltage caused weld bead height trend to decrease but resulted in increased a bead width. However, at arc voltage 29 volt with 0.7 feeding ratio caused defect as discussed previously.

The combined effect of feeding ratio and travel speed on the height of cladding bead (contour lines) was shown in Fig. 8. It was interesting that the bead height insignificant decreased when travel speed was increased as double. Bead heights could be varied only 1.5 millimeter. It implies that bead width may be more significantly affected. In the aspect of process control, bead height could be minimized controlled (height $\sim 4.5$ $\mathrm{mm}$ ) by the highest speed of $60 \mathrm{~cm} / \mathrm{min}$ with the wire feeding ratio 0.5 .

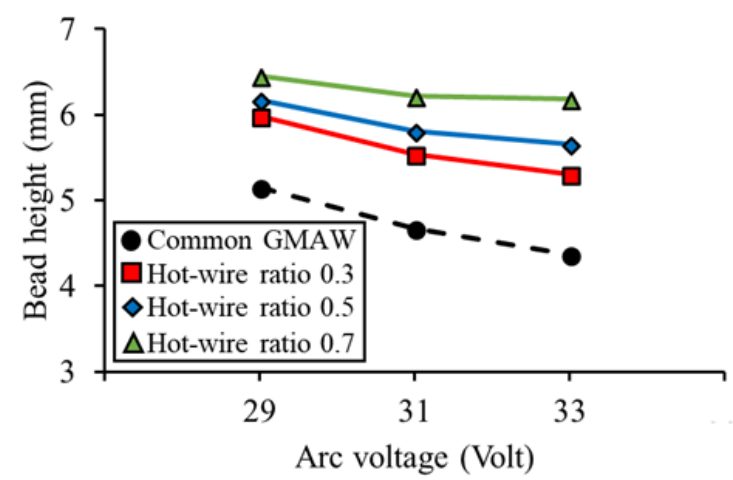

Fig. 7. The cladding bead height under effect of arc voltage and hot-wire feeding ratio.

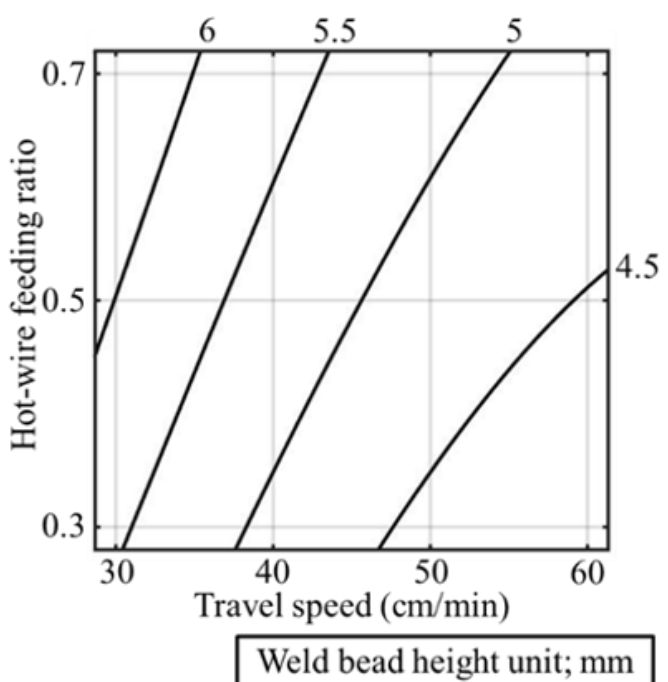

Fig. 8. Contour plot for cladding bead height with cladding parameters by hot-wire GMAW. 


\subsection{Effect of cladding parameters on weld bead width}

Fig. 9 shows the effect of arc voltage and Hot-wire feeding ratio on the width of cladding bead. The weld bead width was improved $7 \%, 14 \%$ and $17 \%$ follow the hot-wire feeding ratio from $0.3,0.5$ and 0.7 respectively. It can be seen that the feed ratio significantly affects the bead width for all of the feeding ratio when the low arc voltage of 29 volt was used. However, arc voltage of 29 volt was mentioned that promoted a poor bead results then it was ignored for parameter selection. While the high arc voltage of 33 volt, feed ratio does not significantly affect the bead width in case of high feeding ratio 0.5 and 0.7 . The reason of this phenomena is a saturated wetting ability of the weld pool under the maximum of the hot-wire power source. Arc voltage of 31 volt was preferentially used for discussion in the next part since as this voltage could provide a satisfied bead size both of height and width with a good appearance.

The combination effect of travel speed and hot-wire feeding ratio on the width of cladding bead was shown in Fig. 10. The increasing of travel speed results in a quite significant decrease in the width of cladding bead.

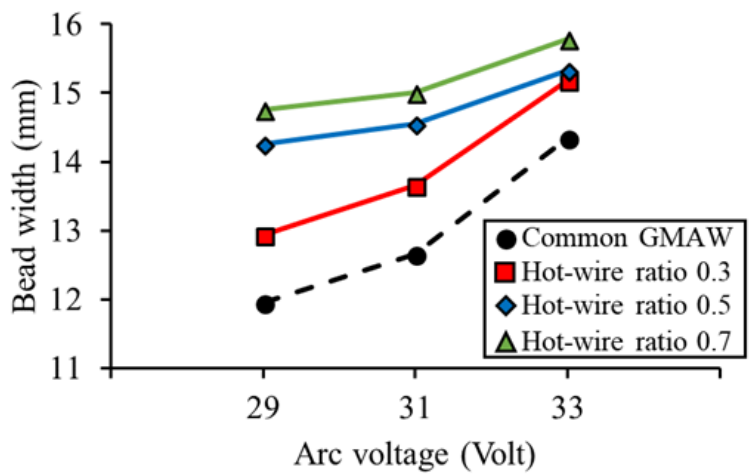

Fig. 9. The cladding bead width under effect of arc voltage and hot-wire feeding ratio.

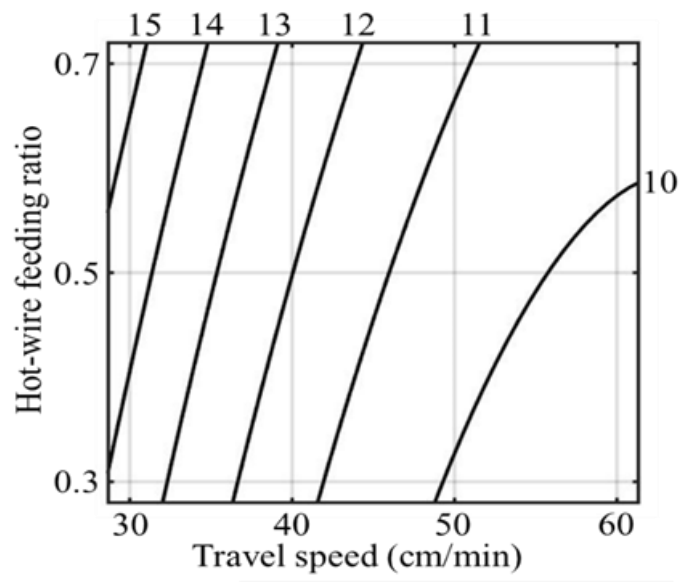

Weld bead width unit; $\mathrm{mm}$

Fig. 10. Contour plot for cladding bead width with cladding parameters by hot-wire GMAW.

\subsection{An advantage of single-pass run with double layers by hot-wire GMAW}

Discussion in the productivity aspect, the cycle time with a unit of cladding area was considered. The Hot-wire GMAW condition was preferentially selected by high speed production which set of parameters as arc voltage 31 volt, hot-wire feeding ratio 0.7 and travel speed at 60 $\mathrm{cm} / \mathrm{min}$ with the single-pass run. By this condition could provide an acceptable cladding bead width with the shortest cladding time and also provided dilution 15\% as illustrated the cross-section in Fig. 6. While FCAW condition was, welding current of 290 ampere, arc voltage of 29 volt, and travel speed of $60 \mathrm{~cm} / \mathrm{min}$, used for comparison. Double-pass run which consists of the idle time of interpass temperature and grindingprocessing time was necessary performed in FCAW. The Hot-wire GMAW could reduce cycle time 3.5 times compared to conventional FCAW.

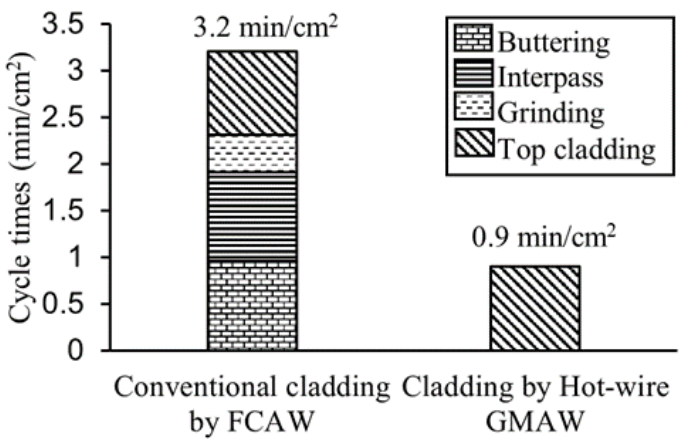

Fig. 11. Comparison of cycle time between conventional cladding by FCAW to cladding by hot-wire GMAW process.

\subsection{Verification of weldability of the cladding bead}

The microstructure with optimal welding condition was investigated by using Scanning Electron Microscope (SEM) and a calibrated ferrite scope to ensuring that the proposed process can provide a process capability in term of a suitable solidified microstructure and usability. According to weldability and usability of austenitic stainless-steel weld [5], the top surface of cladding layer should contain ferrite number in range 3-10 FN. The SEM micrograph shows (Fig. 12) the evidence of delta ferrite in an austenitic structure without cracking defect and result of FN measurement was FN 3

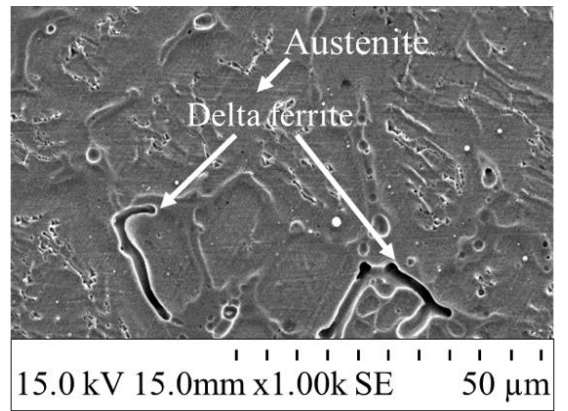

Fig. 11. The microstructure on top surface of hot-wire GMAW that shows austenitic structure with measured delta ferrite FN3. 


\section{Conclusions}

In this research effect of arc voltage, travel speed and hot-wire feeding ratio on the height and the width cladding-bead were studied. It can be concluded that:

(1) The increasing of arc voltage affects to increased weld bead in width area, but the addition of high feeding ratio with low arc voltage caused poor clad-bead appearance.

(2) Addition of hot-wire to GMAW process could improve bead height $19 \%, 25 \%$ and $33 \%$, and bead width $7 \%, 14 \%$ and $17 \%$ follow hot-wire feeding ratio $0.3,0.5$ and 0.7 respectively with a complete cladding layer by a single-pass run.

(3) The bead widths were significantly affected by the travel speeds. Increasing the travel speed resulted in decreasing of the bead width.

(4) The cycle time could be reduced the cladding process by hot-wire GMAW as 3.5 times compared with conventional cladding by FCAW.

\section{References}

1. J.R. Davis, ASM Specialty Handbook: Stainless Steels, 107 (2006)

2. J.H.F. Gomes, S.C. Costa, A.P. Paiva, P.P. Balestrassi, JMEP, 21, 1862 (2012)

3. K. Shinozaki, M. Yamamoto, Y. Nagamitsu, T. Uchida, K. Mitsuhata, T. Nagashima, H. Arashin, JStage, 27, 22 (2009)

4. B.K. Henon, Arc Machines Inc Google Scholar, 2011

5. K.N. Krishnan, K.P. Rao, MSE : A, 142, 79(1991) 